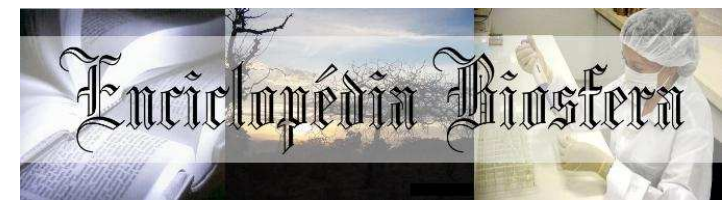

\title{
MONITORAMENTO AMBIENTAL EM UM LABORATÓRIO ACADÊMICO DE ENGENHARIA QUÍMICA: ÊNFASE NA QUALIDADE DO AR INTERIOR
}

Ana Clara Matias Alves ${ }^{1}$, Paula de Freitas Rosa², Mônica Lopes Aguiar ${ }^{3}$

1 Mestranda em Engenharia Química da Universidade Federal de São Carlos

(clarasevla@gmail.com) São Paulo - Brasil

2 Doutoranda em Engenharia Química da Universidade Federal de São Carlos

3 Professora Doutora do Departamento de Engenharia Química da Universidade

Federal de São Carlos

Recebido em: 08/09/2015 - Aprovado em: 14/11/2015 - Publicado em: 01/12/2015

DOI: http://dx.doi.org/10.18677/Enciclopedia_Biosfera_2015_049

\begin{abstract}
RESUMO
O material particulado quando emitido em altas concentrações é considerado extremamente danoso, pois pode provocar diversos problemas de saúde e graves riscos de cunho ambiental. Logo, este estudo teve como objetivo realizar o monitoramento ambiental no laboratório acadêmico do departamento de engenharia química da Universidade Federal de São Carlos - São Carlos/SP. Para tal, o monitoramento interno do laboratório foi realizado durante 8 horas por dia, em um período de 5 dias aleatórios do mês de agosto de 2015, compreendendo a carga horária de 40 horas semanais. O Personal Environmental Monitor (PEM), foi utilizado para a coleta simultânea de particulados, através do uso de membranas de teflon com $37 \mathrm{~mm}$ de diâmetro e diâmetro de poros de $2 \mu \mathrm{m}$. As análises das frações respiráveis de material particulado ocorreram mediante a técnica de Fluorescência de raios-X (FRX) a 600s no vácuo e também pela técnica de Microscopia Eletrônica de Varredura (MEV) com resolução de 2.500 x. As concentrações de MP10 variaram na faixa de 447,5 a $823,1 \mu \mathrm{g} / \mathrm{m}^{3}$, apresentando uma média de $596,5 \mu \mathrm{g} / \mathrm{m}^{3}$. Já as concentrações de $\mathrm{MP}_{2,5}$ estiveram na faixa entre 130,8 a 346,2 $\mu \mathrm{g} / \mathrm{m}^{3}$, com média de $225,18 \mu \mathrm{g} / \mathrm{m}^{3}$. Foi possível constatar por intermédio da composição química semiquantitativa elementos na faixa de $\mathrm{Al}$ a $\mathrm{Zn}$, e pela análise quantitativa foi verificado os percentuais dos elementos mais significativos. As concentrações encontradas tanto para $\mathrm{MP}_{10}$ quanto para $\mathrm{MP}_{2,5}$ são consideradas altas, o que representa um ponto negativo aos indivíduos que estão sendo submetidos a este tipo de exposição.
\end{abstract}

PALAVRAS-CHAVE: atmosfera, material particulado, qualidade do ar

\section{ENVIRONMENTAL MONITORING IN AN ACADEMIC LABORATORY OF CHEMICAL ENGINEERING: EMPHASIS ON INDOOR AIR QUALITY}

\begin{abstract}
The particulate material emitted in high concentrations is considered extremely damaging for it can cause several health problems and serious environmental risks. In this way, this study aimed to carry out the environmental monitoring in the
\end{abstract}


academic laboratory of the department of chemical engineering at Federal University of São Carlos - São Carlos/SP. The internal monitoring of the laboratory was conducted for 8 hours per day during a period of 5 random days of August 2015, comprising a workload of 40 hours per week. The Personal Environmental Monitor (PEM) was used for simultaneous collection of particulate material through the use of Teflon membranes with $37 \mathrm{~mm}$ diameter with pores of $2 \mu \mathrm{m}$. The analyzes of the breathable fractions of particulate material occurred through the Fuorescence X-ray (XRF) technique to 600s in vacuum and also by the Electron Microscopy technique (SEM) with a resolution of $2500 x$. The $\mathrm{PM}_{10}$ concentrations varied in range from 447.5 to $823.1 \mu \mathrm{g} / \mathrm{m}^{3}$, whit an average of $596.5 \mu \mathrm{g} / \mathrm{m}^{3}$. For concentrations of $\mathrm{PM}_{2,5}$ the range was from 130.8 to $346.2 \mu \mathrm{g} / \mathrm{m}^{3}$, with an avererage of $225.18 \mu \mathrm{g} / \mathrm{m}^{3}$. It was possible to observe through the semi-quantitative chemical composition analysis, elements from $\mathrm{Al}$ to $\mathrm{Zn}$ and the quantitative analysis was verified the elementary percentage most significant. The concentration detected both $\mathrm{PM}_{10}$ and $\mathrm{PM}_{2,5}$ are considered high, which they represent a negative point to individuals who are being subjected to this kind of exposure.

KEYWORDS: atmosphere, particulate matter, air quality

\section{INTRODUÇÃO}

O nível de poluição atmosférica, também denominado qualidade do ar, é correlacionado com a interação entre as fontes poluidoras, a atmosfera e as condições meteorológicas locais, como a temperatura, umidade, direção dos ventos e precipitação pluviométrica, que influenciam a intensidade da dispersão de poluentes. A correlação das consequências da poluição atmosférica e os danos à saúde justificou o princípio da criação de órgãos ambientais como a Agência de Proteção Ambiental (EPA) em esfera internacional, no ano de 1970 e o Conselho Nacional do Meio Ambiente (CONAMA) em esfera nacional, no ano de 1981 (ANDREOLI, 1991).

A priori, os estudos e legislações de cunho ambiental eram alicerçados de modo geral, apenas em ambientes externos. Entretanto, com a descoberta de que baixas trocas de ar em ambientes externo e interno promovem um significante acréscimo na concentração de poluentes químicos e biológicos, as pesquisas sobre qualidade do ar de interiores (QAI) foram alcançando notoriedade, com o foco de controlar os fatores que alteram as condições do ambiente, almejando a máxima comodidade ambiental e o mínimo prejuízo à saúde.

É válido ressaltar que são inúmeros os elementos que interferem nas condições de um ambiente interno, dentre eles, destacam-se as particularidades do ambiente externo, as características construtivas do prédio e sua rotina, além da quantidade de ocupantes no local e as atividades desenvolvidas pelos mesmos. Um dos ambientes internos que tem motivado o interesse de estudos é o ambiente do trabalhador. Dessa forma, a justificativa da importância de atentar-se para a QAI em locais de trabalho dar-se-á pelo tempo de exposição a potenciais substâncias tóxicas acima dos níveis toleráveis, com consequente determinação de insalubridade.

Nessa perspectiva, os laboratórios acadêmicos se enquadram na modalidade de ambiente interno de trabalho e carecem constantemente de estudos na área, uma vez que diariamente durante a realização das atividades são manuseados diversos reagentes, materiais particulados, soluções e equipamentos variados.

Logo, diante do que foi exposto, o objetivo geral do trabalho foi realizar o monitoramento ambiental no laboratório acadêmico do departamento de engenharia 
química da Universidade Federal de São Carlos - SP em uma carga horária de trabalho de 40 horas. Porém, perante a vasta gama de opções para se estudar neste ambiente, apenas os seguintes objetivos específicos foram traçados:

- Monitorar as concentrações das frações respiráveis de material particulado $\left(\mathrm{MP}_{2,5}\right.$ e $\left.\mathrm{MP}_{10}\right)$ em ambiente interno;

- Realizar a caracterização química e física do particulado coletado;

- Medir a temperatura e a umidade relativa do ar;

- Correlacionar dados obtidos com as possíveis doenças suscetíveis via exposição direta.

A motivação pelo desenvolvimento deste estudo dar-se-á pela sua importância, e a escolha do local baseou-se no fato de ser um ambiente em que professores, técnicos e alunos são expostos diariamente a condições de trabalho consideradas muita das vezes como insalubres.

\section{Local de estudo}

\section{MATERIAL E MÉTODOS}

Localizada no centro geográfico do Estado de São Paulo a 250 km da capital, São Carlos é uma cidade que fica próxima a Araraquara, Rio Claro e Ribeirão Preto, tornando essa macrorregião uma das mais desenvolvidas do Estado. A cidade possui altitude média de 856 metros, uma população estimada em 238.958 habitantes (IBGE, 2015) e o clima é conhecido como tropical de altitude, apresentando verão chuvoso e inverno seco (EMPRAPA, 2015). Ademais, abriga duas das melhores universidades do país, a Universidade de São Paulo (USP) e a Universidade Federal de São Carlos.

Fundada em 1968 a Universidade Federal de São Carlos é a única instituição federal de ensino superior localizada no interior do estado de São Paulo, e encontrase situada na Rodovia Washington Luís, Km 235, São Carlos - SP (UNIVERSIDADE FEDERAL DE SÃO CARLOS, 2015).

O campus São Carlos possui 300 laboratórios e destes, o laboratório monitorado encontra-se disposto no Departamento de Engenharia Química (DEQ), área norte da universidade. Esse laboratório possui uma área de $35 \mathrm{~m}^{2}$, atende alunos de graduação e pós-graduação (mestrado, doutorado e pós-doutorado), além de professores e técnicos, todos na faixa etária de 17 a 65 anos. O local de trabalho é amplo, arejado, de luminosidade alta e com disponibilidade de equipamentos de grandes dimensões, como pode ser verificado na Figura 1 (a) e (b).
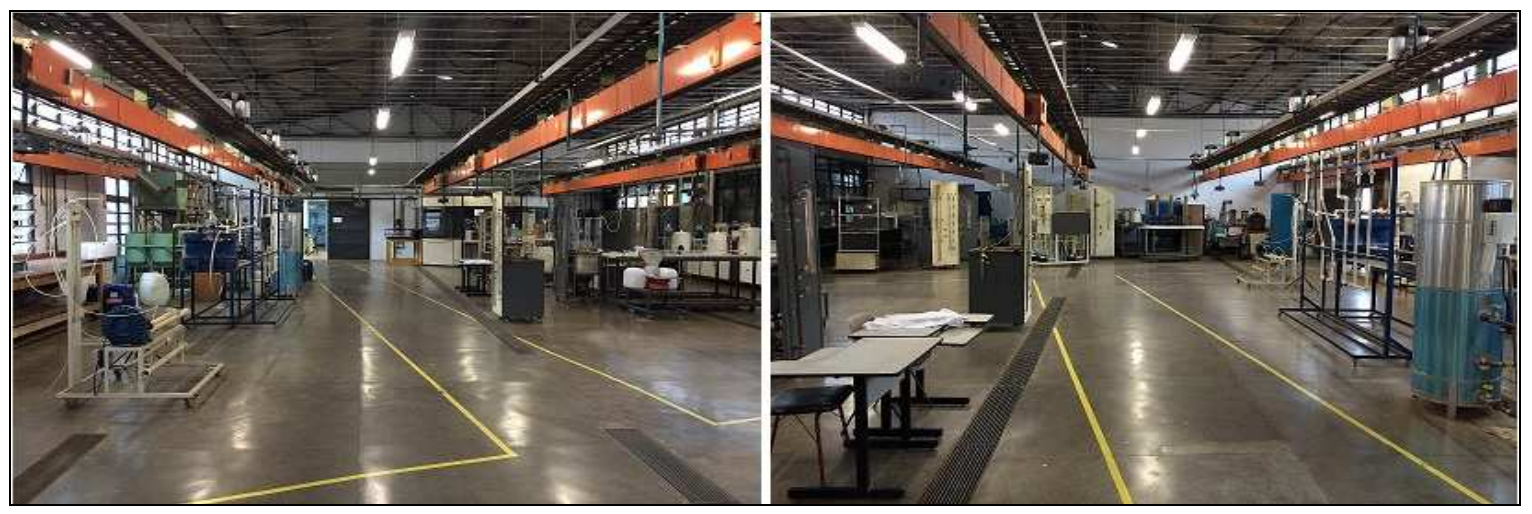

FIGURA 1 (a) e (b) - Laboratório do departamento de Engenharia Química da Universidade Federal de São Carlos - DEQ/UFSCa

Fonte: Arquivo pessoal.

ENCICLOPÉDIA BIOSFERA, Centro Científico Conhecer - Goiânia, v.11 n.22; p. 3352 


\section{Material particulado}

Para realizar o monitoramento das frações respiráveis de particulados $\left(\mathrm{MP}_{2,5}\right.$ e MP10), foi utilizado o equipamento portátil Personal Environmental Monitor (PEM) da marca SKC, dispositivo pequeno e compacto de amostragem pessoal, constituído essencialmente por três partes principais: capa, conjunto do anel de impactação e base com pós-filtro. Na superfície da capa, há projeções de formato circular por onde o fluxo de ar entra no amostrador que funciona vinculado a uma bomba Leland Legacy, marca SKC, que succiona o ar a uma vazão de $10 \mathrm{~L} / \mathrm{min}$ e o passa através do PEM, retendo o material particulado de diâmetro equivalente ao da membrana.

O uso do PEM (Figura 2) é apropriado para estudos de poluição do ar, avaliações de qualidade do ar de interiores e amostragem pessoal para aplicações na indústria com a finalidade de monitorar os possíveis causadores de doenças respiratórias.

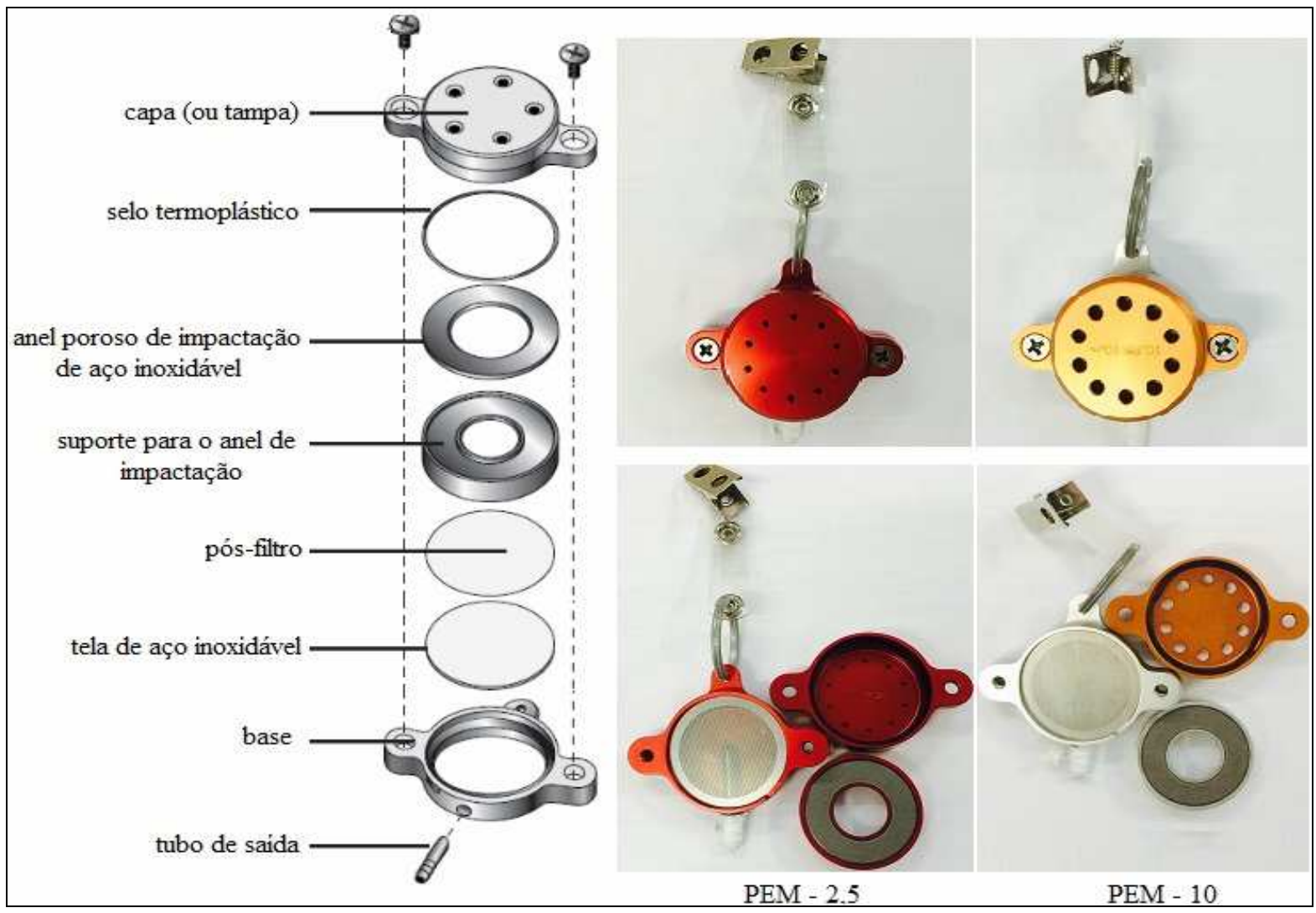

FIGURA 2 - Partes constituintes do PEM - 2,5 e PEM - 10

Fonte: Adaptação da figura disponível em SKC (2011).

O princípio de operação deste equipamento baseia-se na separação inercial de partículas presentes no ar. Dessa forma, elas são coletadas por intermédio do impactador, descartando as partículas acima de $50 \%$ do ponto de corte de 2,5 ou 10 $\mu \mathrm{m}$ de diâmetro aerodinâmico, dependendo da fração amostrada. Desta maneira, as partículas maiores ficam confinadas em um anel lubrificado com vaselina e são removidas após a amostragem, enquanto as partículas menores, aquelas abaixo dos $50 \%$ do ponto de corte, são recolhidas em membranas de teflon de $37 \mathrm{~mm}$ de diâmetro e $2 \mu \mathrm{m}$ de diâmetro de poro, observada na Figura 3 (a) e (b). 


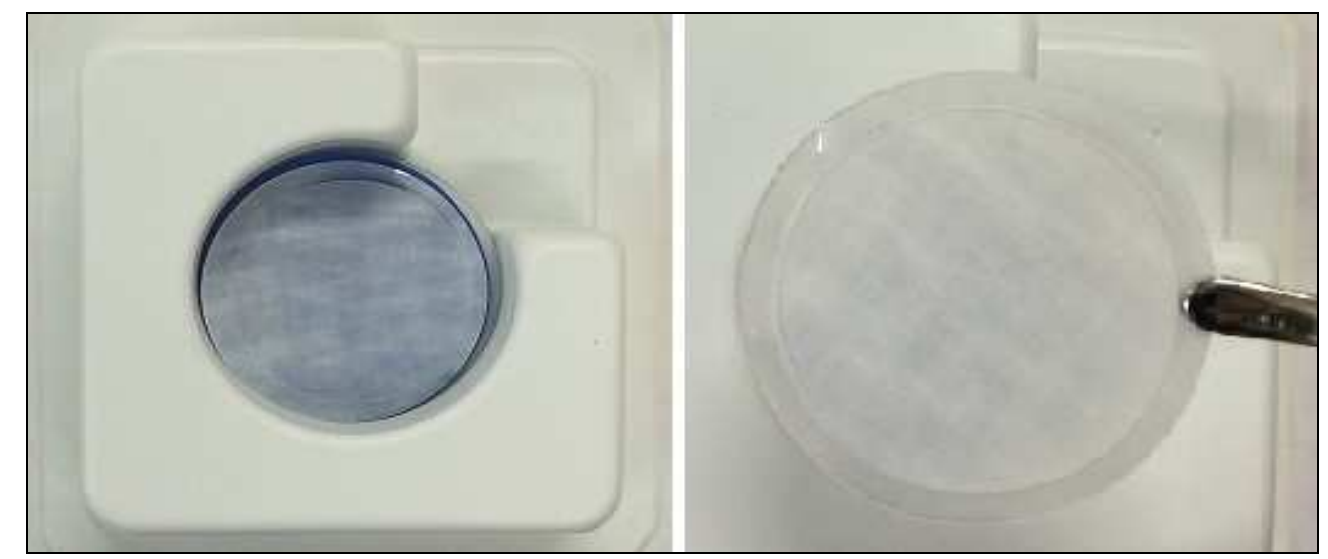

FIGURA 3 (a) e (b) - Membrana de teflon de $37 \mathrm{~mm} 2 \mu \mathrm{m}$ de Fonte: Acervo pessoal. diâmetro de poro

O monitoramento interno do laboratório foi realizado durante 8 horas por dia, em um período de cinco dias aleatórios do mês de agosto de 2015, compreendendo a carga horária total de 40 horas. A amostragem teve início às 9:00 horas da manhã e término às 17:00 horas. É válido ressaltar que todas as membranas ficaram dispostas durante o período de 24 horas próximas ao sistema de ionização, para a eliminação de cargas eletrostáticas, com consequente interferência no processo de pesagem.

Em seguida, as membranas foram pesadas duas vezes com a finalidade de aumentar a precisão na obtenção das massas iniciais (antes da coleta) e finais (depois da coleta) e após, foi determinada a média aritmética. A totalidade do volume de ar amostrado foi obtida através da bomba SKC, que exibia em seu visor a respectiva quantidade. Já o cálculo da massa retida, foi efetuado mediante o processo de pesagem das membranas filtrantes antes e após a amostragem.

A fim de conter possíveis interferências de cargas eletrostáticas nas pesagens, utilizou-se a microbalança com precisão de sete casas decimais, marca Mettler Toledo, modelo UMX2, que apresenta um sistema de ionização, possibilitando a eliminação das cargas eletrostáticas, instalada no laboratório de Controle Ambiental I do Departamento de Engenharia Química da UFSCar.

\section{Análise do material particulado por Fluorescência de raios-X (FRX)}

Para a identificação dos elementos químicos presentes nas membranas amostradas, utilizou-se a técnica da Fluorescência de raios-X (FRX). Essa técnica também foi empregada em outros trabalhos como o de MATSUMOTO (2001), NASCIMENTO FILHO (1999) e COMIN (2012).

A técnica FRX é um método não destrutivo, quali/quantitativo baseada na utilização de sinais de raios- $X$ para excitar as amostras desconhecidas a 600 segundos no vácuo. Assim, os elementos químicos emitem seus raios- $X$ característicos, determinando o espectro presente nas amostras (MELO JÚNIOR, 2007).

Dessa maneira, as membranas empregadas nos PEM's foram analisadas no Laboratório de Caracterização Estrutural (LCE), do Departamento de Engenharia de Materiais (DEMa) da Universidade Federal de São Carlos (UFSCar), por um espectrômetro de fluorescência de raios-X por energia dispersiva, modelo EDX-720, da marca Shimadzu (Figura 4), com limite de detecção para os elementos de número atômico entre sódio $(Z=11)$ e urânio $(Z=92)$. 


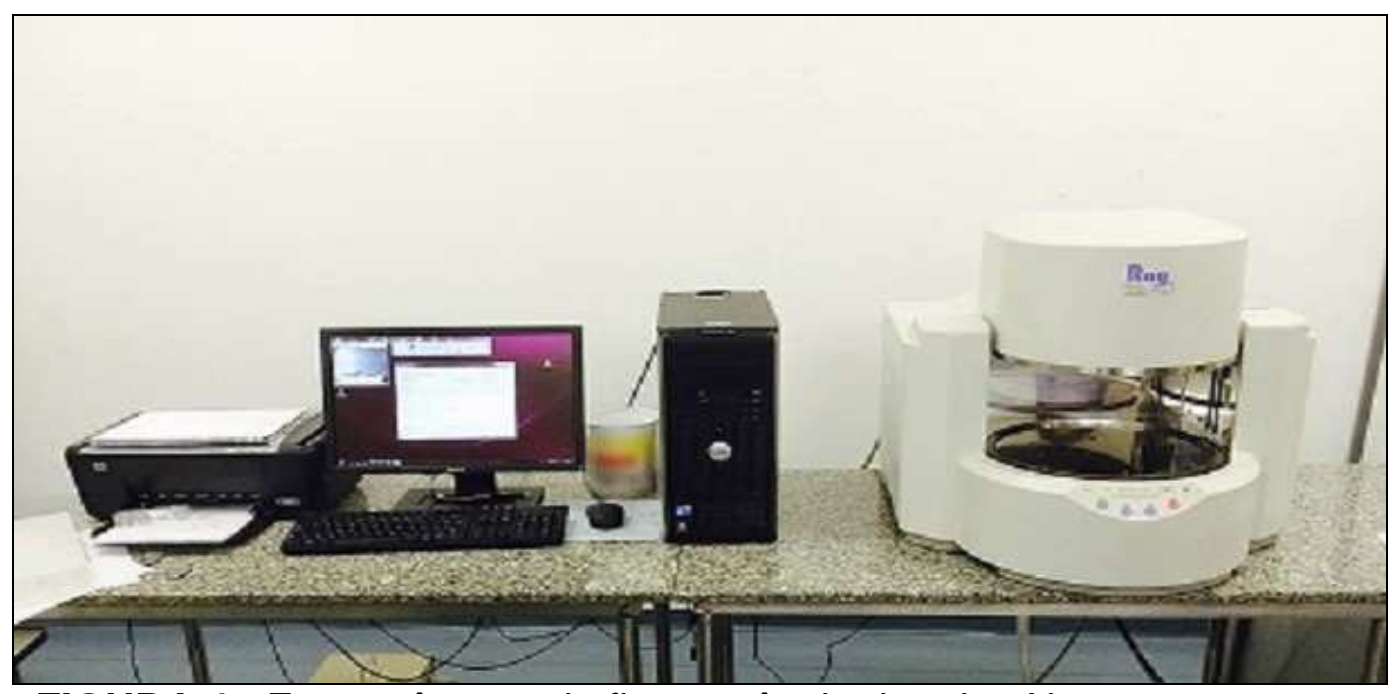

FIGURA 4 - Espectrômetro de fluorescência de raios-X

Fonte: Arquivo pessoal.

\section{Análise do material particulado por Microscopia Eletrônica de Varredura}

Para a determinação da estrutura física do particulado coletado, foi utilizada a técnica de Microscopia Eletrônica de Varredura, empregada também nos trabalhos de MAIOLI (2011), GONÇALVES JÚNIOR (2014) e ROSA (2014).

O princípio de funcionamento da técnica baseia-se na interação do feixe de elétrons de alta energia com a amostra, resultando na liberação de uma faixa de radiações, sendo os sinais de maior interesse os elétrons secundários e os raios- $X$ precursores da imagem de alta resolução e sua respectiva caracterização química (MANNHEIMER, 2002).

Essa técnica ainda é bastante recente para estudos de caracterização de material particulado atmosférico e a mesma é capaz de definir a morfologia do material em análise, através da produção de imagens de alta resolução e ampliação sob um aumento de até 300.000 vezes, além de permitir determinar a composição química dos aerossóis (MANNHEIMER, 2002).

Logo, as membranas empregadas nos PEM's foram analisadas também no Laboratório de Caracterização Estrutural (LCE), do Departamento de Engenharia de Materiais (DEMa) da Universidade Federal de São Carlos (UFSCar), pelo microscópio eletrônico de varredura (MEV Inspect) modelo S50, da marca FEI (Figura 5).

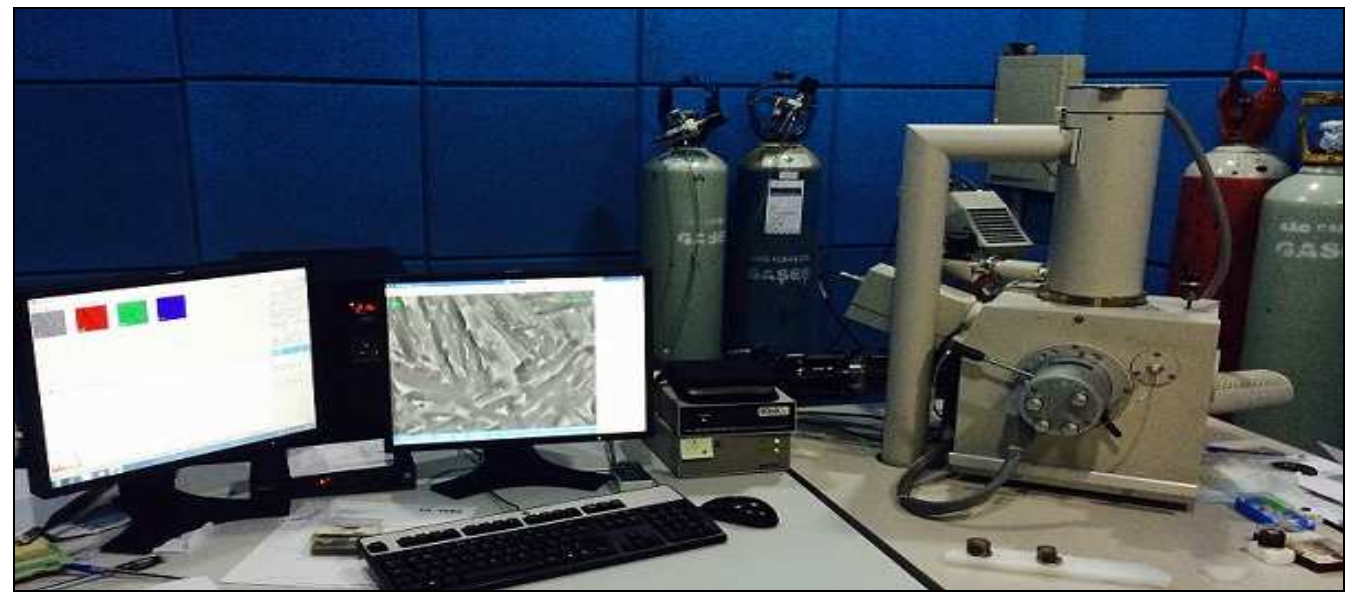

FIGURA 5 - Microscópio eletrônico de varredura (MEV Inspect)

Fonte: Arquivo pessoal. 


\section{Temperatura e Umidade relativa}

O monitoramento da temperatura e da umidade relativa foi efetuado tendo como base a Norma Técnica 003 da Resolução - RE no 9, de 16 de janeiro de 2003 da AGÊNCIA NACIONAL DE VIGILÂNCIA SANITÁRIA (ANVISA), que propõe a utilização de um amostrador de leitura direta, do tipo termohigrômetro com faixa de temperatura entre 0 a $70 \stackrel{\circ}{\circ}$ e umidade de $5 \%$ a $95 \%$. Nessa perspectiva, utilizou-se um termohigrômetro digital, marca Rotronic, modelo Hygropalm-0, que apresenta sensores externos de temperatura (Pt100 1/3DIN) e umidade (Hygromer) e possui proteção por filtro aramado, que facilita a troca térmica e aumenta a velocidade de resposta, o que o deixa mais eficiente.

Entretanto, o equipamento em questão embora seja portátil, não armazena os dados continuamente, inviabilizando que os mesmos sejam descarregados em um computador. Logo, as aferições de temperatura e umidade relativa, foram efetuadas ao início e ao término de cada amostragem e depois de transcritas, foram calculadas as respectivas médias aritméticas.

\section{RESULTADOS E DISCUSSÕES \\ Frações respiráveis amostradas com o Personal Environmental Monitor (PEM)}

Devido a disponibilidade de um PEM10 e outro $\mathrm{PEM}_{2,5}$ para as coletas, foi possível coletar simultaneamente as concentrações de $\mathrm{MP}_{10}$ e $\mathrm{MP}_{2,5}$ totalizando a quantidade de cinco amostras de cada.

As Tabela 1 e 2 apresentam quantitativamente a massa retida através do $\Delta \mathrm{m}$, o volume de ar obtido durante cada amostragem e as concentrações de $\mathrm{MP}_{10} \mathrm{e}$ $\mathrm{MP}_{2,5}$. O cálculo é efetuado pela relação do $\Delta \mathrm{m}$ dividido pelo volume de ar e multiplicado pela unidade de medida correspondente, que no caso foi $\mu \mathrm{g} / \mathrm{m}^{3}$.

TAELA 1 - Concentrações de MP10 calculadas para membranas utilizadas no PEM10

\begin{tabular}{cccccc}
\hline Amostra & $\begin{array}{c}\text { Massa inicial } \\
(\mathrm{mg})\end{array}$ & $\begin{array}{c}\text { Massa final } \\
(\mathrm{mg})\end{array}$ & $\begin{array}{c}\Delta \mathrm{m}=\mathrm{Mf}-\mathrm{Mi} \\
(\mathrm{mg})\end{array}$ & $\begin{array}{c}\text { Volume de ar } \\
\left(\mathrm{m}^{3}\right)\end{array}$ & $\begin{array}{c}\text { Concentração } \\
\left(\mu \mathrm{g} / \mathrm{m}^{3}\right)\end{array}$ \\
\hline 1 & 99,509 & 102,271 & 2,76 & 4,00 & 690,0 \\
2 & 104,089 & 105,900 & 1,81 & 4,02 & 450,2 \\
3 & 105,335 & 107,555 & 2,23 & 3,90 & 571,8 \\
4 & 102,794 & 104,586 & 1,79 & 4,00 & 447,5 \\
5 & 109,332 & 112,544 & 3,21 & 3,90 & 823,1 \\
\hline
\end{tabular}

Fonte: Elaborado pelas autoras.

TABELA 2 - Concentrações de MP 2,5 calculadas para membranas utilizadas no $\mathrm{PEM} 2,5$

\begin{tabular}{cccccc}
\hline Amostra & $\begin{array}{c}\text { Massa inicial } \\
(\mathbf{m g})\end{array}$ & $\begin{array}{c}\text { Massa final } \\
(\mathbf{m g})\end{array}$ & $\begin{array}{c}\mathbf{\Delta} \mathbf{m}=\mathbf{M f}-\mathbf{M i} \\
(\mathbf{m g})\end{array}$ & $\begin{array}{c}\text { Volume de ar } \\
\left(\mathbf{m}^{3}\right)\end{array}$ & $\begin{array}{c}\text { Concentração } \\
\left(\boldsymbol{\mu g} / \mathbf{m}^{3}\right)\end{array}$ \\
\hline 1 & 100,707 & 101,623 & 0,92 & 4,00 & 230,0 \\
2 & 103,987 & 104,854 & 0,87 & 4,02 & 216,4 \\
3 & 97,743 & 99,089 & 1,35 & 3,90 & 346,2 \\
4 & 102,116 & 102,922 & 0,81 & 4,00 & 202,5 \\
5 & 108,294 & 108,805 & 0,51 & 3,90 & 130,8 \\
\hline
\end{tabular}

Fonte: Elaborado pelas autoras.

De modo mais sucinto e com a finalidade de facilitar a visualização, as concentrações do Material Particulado de diâmetro de 10 e 2,5 um (MP10 e 2,5) podem ser observadas também na Figura 6. 


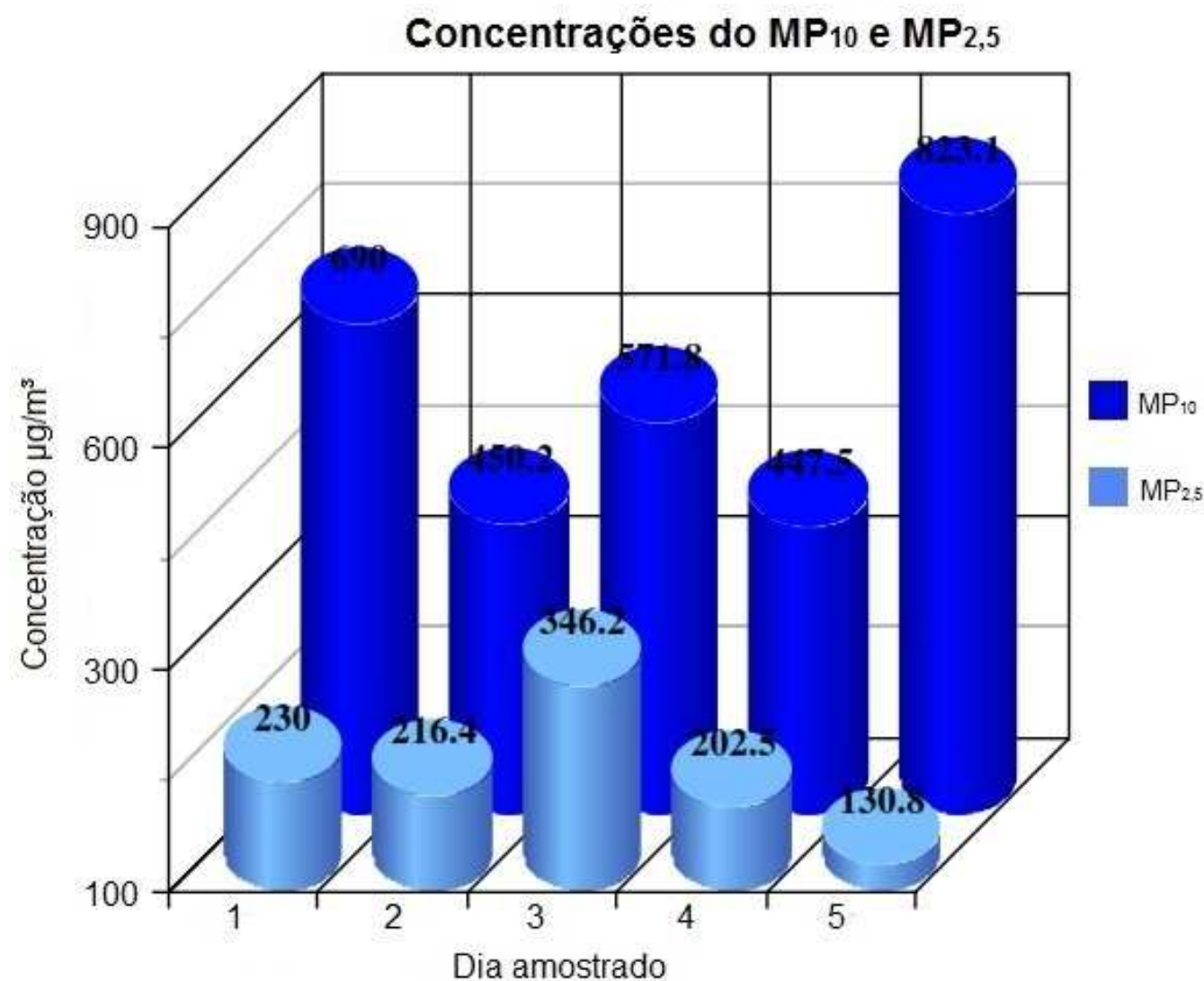

FIGURA 6 - Gráfico com as concentrações de $\mathrm{MP}_{10}$ e $\mathrm{MP}_{2,5}$

Fonte: Elaborado pelas autoras.

A Companhia Ambiental do Estado de São Paulo (CETESB) e a Organização Mundial da Saúde (OMS), preveem $25 \mu \mathrm{g} / \mathrm{m}^{3}$ como valor máximo para a concentração média de $\mathrm{MP}_{2,5}$ e $50 \mu \mathrm{g} / \mathrm{m}^{3}$ para a concentração média $\mathrm{MP}_{10}$, em amostragens com período de 24 horas, realizadas em ambientes externos.

Já a Agência Nacional de Vigilância Sanitária (ANVISA) através da RE 09/2003, recomenda $80 \mu \mathrm{g} / \mathrm{m}^{3}$ como valor máximo para a concentração média de Material Particulado Total (MPT), em amostragens com período de 24 horas em ambientes internos. A Associação Brasileira de Refrigeração, Ar Condicionado, Ventilação e Aquecimento (ABRAVA) através da RN 02/2003, estipula para as mesmas condições, o valor máximo de $60 \mu \mathrm{g} / \mathrm{m}^{3}$.

Neste estudo, foram monitoradas as frações respiráveis de $\mathrm{MP}_{10}$ e $\mathrm{MP}_{2,5}$ em ambiente interno, durante 8:00 horas cada amostragem. Tendo em vista o tempo de amostragem, não há nenhuma legislação brasileira que aborde as condições estudadas. Dessa maneira, por ausência de legislações brasileiras específicas, os trabalhos realizados na área são comparados com os padrões já existentes, que muitas das vezes não se ajustam a realidade monitorada.

Pelas Tabelas 1 e 2 e pela Figura 7, é possível verificar que as concentrações de $\mathrm{MP}_{10}$ variaram na faixa de 447,5 a $823,1 \mu \mathrm{g} / \mathrm{m}^{3}$, apresentando uma média de $596,5 \mu \mathrm{g} / \mathrm{m}^{3}$. Já as concentrações de $\mathrm{MP}_{2,5}$ estiveram na faixa entre 130,8 a 346,2 $\mu \mathrm{g} / \mathrm{m}^{3}$, com média de $225,18 \mu \mathrm{g} / \mathrm{m}^{3}$. Observa-se também que as concentrações de $\mathrm{MP}_{10}$ foram superiores as de $\mathrm{MP}_{2,5}$ em todas as amostras analisadas, representando um ponto positivo, visto que as partículas inferiores a $2,5 \mu \mathrm{m}$ são facilmente inaladas. 
Diante do que foi exposto, comparando os dados obtidos com os parâmetros requeridos pelas normas existentes, todos as concentrações extrapolaram os valores máximos estipulados.

\section{Frações respiráveis analisadas por FRX}

Como já descrito anteriormente, a técnica $F R X$ tem um limite elevado de detecção para elementos de número atômico entre sódio $(Z=11)$ e urânio $(Z=92)$. Logo, se o elemento em questão possuir número atômico próximo ou menor que 11 e próximo ou maior que 92, o mesmo não será detectado.

Assim, ao analisar as membranas de teflon em análise semiquantitativa, constataram-se os seguintes elementos químicos:

- MP10: Al, Ca, Cl, Cu, Fe, K, Mg, P, S, Si, Ti, Zn.

- MP2,5: Al, Ba, Ca, Ce, Cl, Cu, Fe, I, K, Mg, P, S, Si, Ti, Zn.

A Tabela 3 e a Figura 7 trazem os percentuais médios dos elementos químicos de maior interesse, efetuados através da análise quantitativa.

TABELA 3 - Análise quantitativa dos elementos químicos

\begin{tabular}{|c|c|c|c|c|c|c|c|c|c|c|c|c|}
\hline \multirow[b]{2}{*}{$\begin{array}{l}\text { Elementos } \\
\text { Químicos }\end{array}$} & \multicolumn{5}{|c|}{ Amostras MP10 (\%) } & \multirow[b]{2}{*}{ Médias } & \multicolumn{5}{|c|}{ Amostras MP2,5 (\%) } & \multirow[b]{2}{*}{ Médias } \\
\hline & 1 & 2 & 3 & 4 & 5 & & 1 & 2 & 3 & 4 & 5 & \\
\hline $\mathrm{Ca}$ & 29,2 & 33,9 & 34,1 & 36,0 & 8,8 & 28,4 & 24,8 & 26,9 & 31,3 & 34,5 & 12,5 & 26,0 \\
\hline $\mathrm{Cu}$ & 0,1 & 0,1 & 0,1 & 0,1 & 0,1 & 0,1 & 0,1 & 0,1 & 0,1 & 0,1 & 0,2 & 0,1 \\
\hline $\mathrm{Fe}$ & 4,0 & 3,4 & 3,1 & 3,5 & 5,0 & 3,8 & 3,8 & 3,1 & 3,0 & 3,1 & 4,0 & 3,4 \\
\hline $\mathrm{K}$ & 11,0 & 12,6 & 13,1 & 11,2 & 13,8 & 12,3 & 11,6 & 12,0 & 12,6 & 12,5 & 28,4 & 15,4 \\
\hline $\mathrm{s}$ & 4,8 & 5,9 & 4,4 & 3,6 & 33,8 & 10,5 & 5,8 & 6,7 & 4,3 & 4,0 & 34,7 & 11,1 \\
\hline $\mathrm{Si}$ & 37,2 & 43,2 & 44,5 & 44,8 & 37,4 & 41,4 & 44,2 & 50,3 & 47,8 & 45,0 & 18,9 & 32,4 \\
\hline $\mathrm{Ti}$ & 13,9 & 0,9 & 0,8 & 1,0 & 1,2 & 3,6 & 9,8 & 1,0 & 0,9 & 0,8 & 1,3 & 2,8 \\
\hline
\end{tabular}

Fonte: Elaborado pelas autoras.

Percentuais médios dos elementos químicos

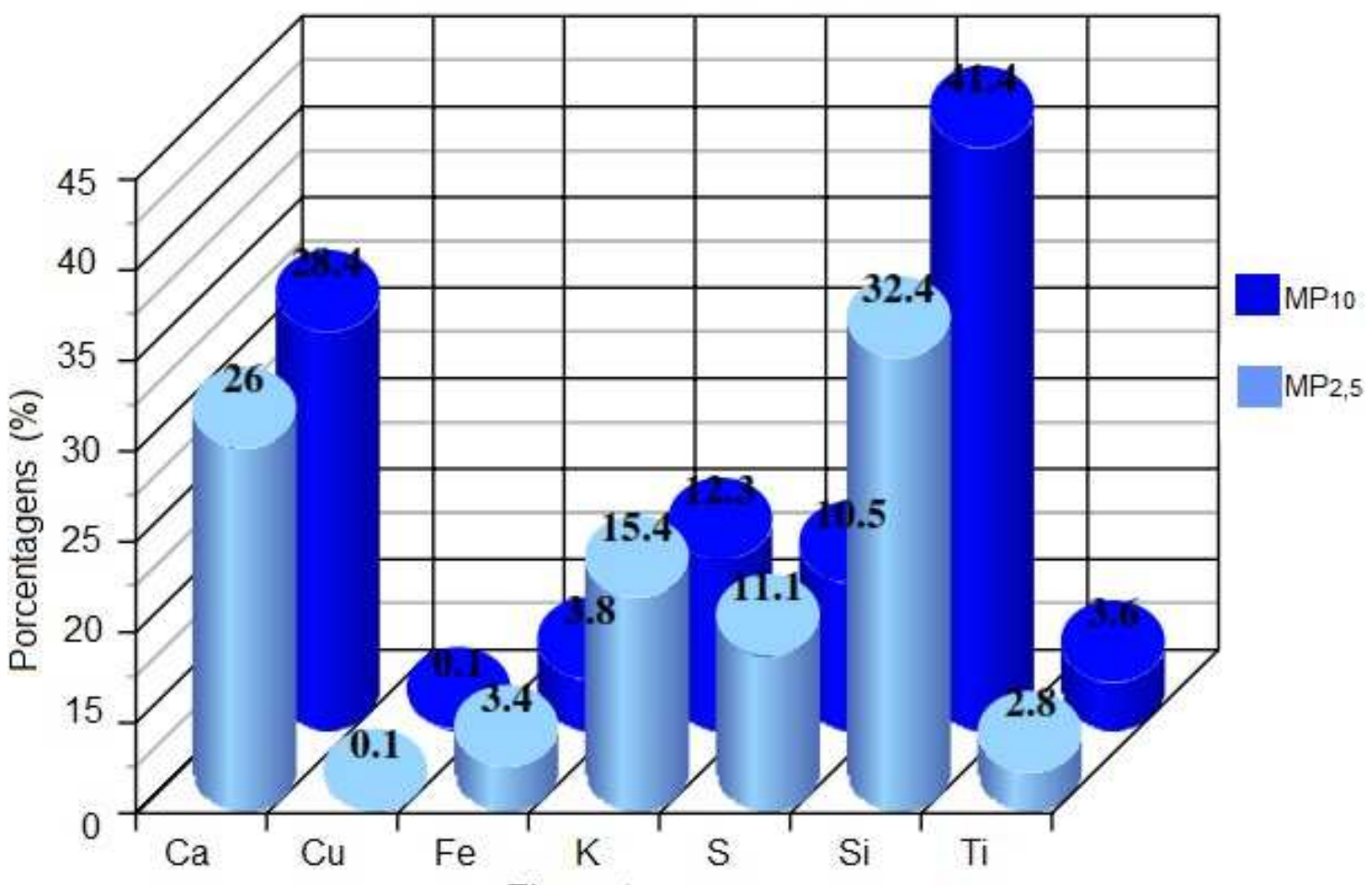

Elementos

FIGURA 7 - Gráfico com os percentuais médios dos elementos químicos

Fonte: Elaborado pelas autoras. 
$\mathrm{Na}$ análise semiquantitativa os elementos foram os mesmos para as frações de $\mathrm{MP}_{10}$ e $\mathrm{MP}_{2,5}$, exceto os elementos $\mathrm{Ba}$, Ce e I que estiveram presentes apenas nas concentrações de $\mathrm{MP}_{2,5}$. Na análise quantitativa, as concentrações de $\mathrm{Si}, \mathrm{S}, \mathrm{Ca}$ e $\mathrm{K}$ foram maiores tanto para o $\mathrm{MP}_{10}$ quanto para o $\mathrm{MP}_{2,5}$. As concentrações de $\mathrm{Fe} e$ de $\mathrm{Cu}$ mantiveram-se em pequenas quantidades. Já as de $\mathrm{Cu}$, mostraram-se irrelevantes para ambos MP.

POZZA (2005) traz em seu trabalho os inventários de fontes de material particulado, porém, na maioria dos casos os elementos detectados advêm na maioria dos casos de emissão veicular, ressuspensão do solo de vias pavimentadas, queima de vegetação rasteira e queima industrial de biomassas.

\section{Frações respiráveis analisadas por MEV}

A Figura 8 (a) - (j), apresenta a análise física do Material Particulado de diâmetro de 10 e 2,5 um (MP10 e 2,5), por Microscopia Eletrônica de Varredura (MEV) de cada amostra, além da linha de composição química pontual, que corresponde aos elementos presentes em uma dada faixa.

Ademais, as imagens obtidas neste estudo, tiveram aumento de resolução de $2.500 \mathrm{x}$, e as linhas vermelhas traçadas por cima de cada imagem, representam a faixa escolhida para a determinação da composição elementar.
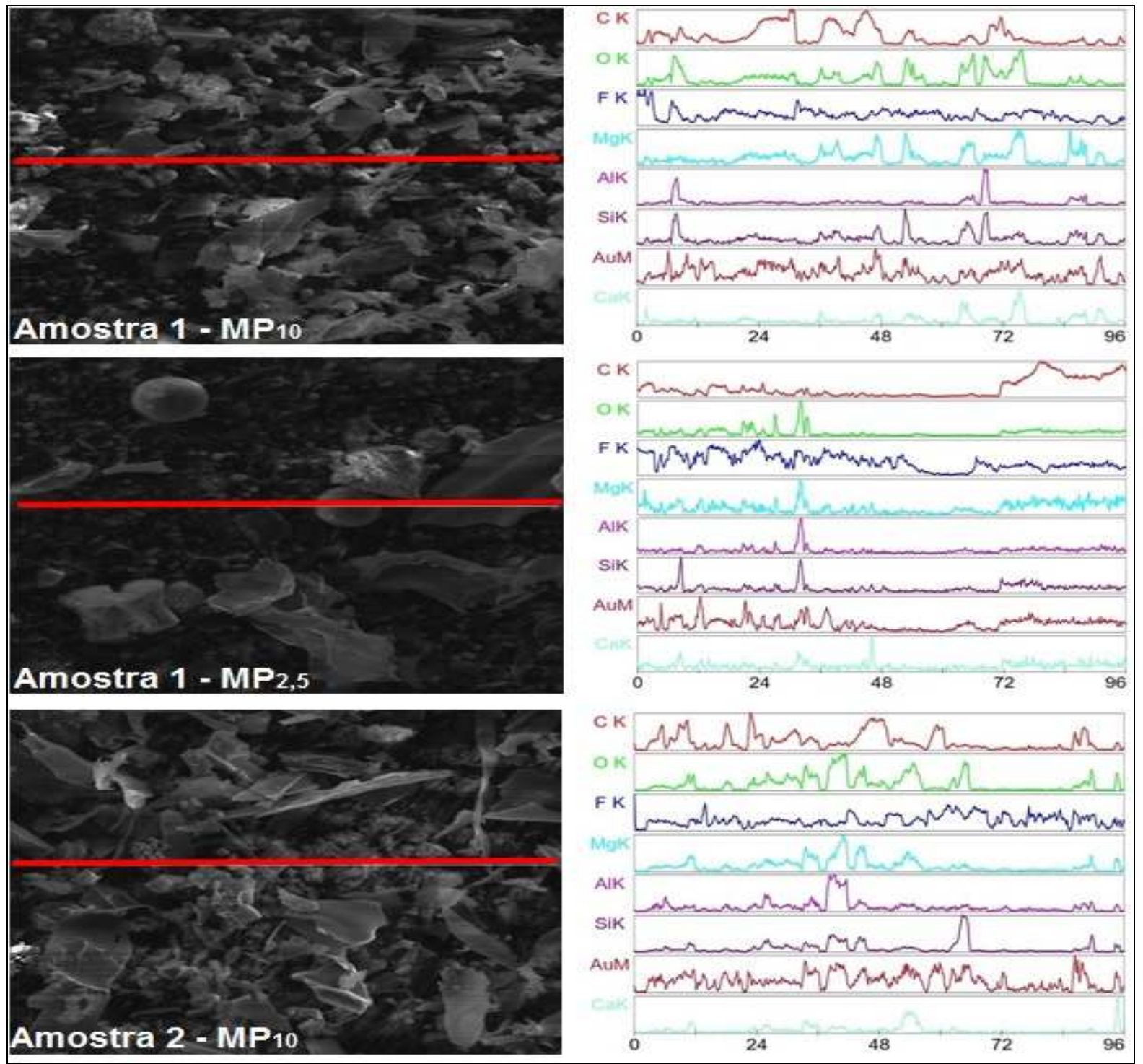

ENCICLOPÉDIA BIOSFERA, Centro Científico Conhecer - Goiânia, v.11 n.22; p. 3359 

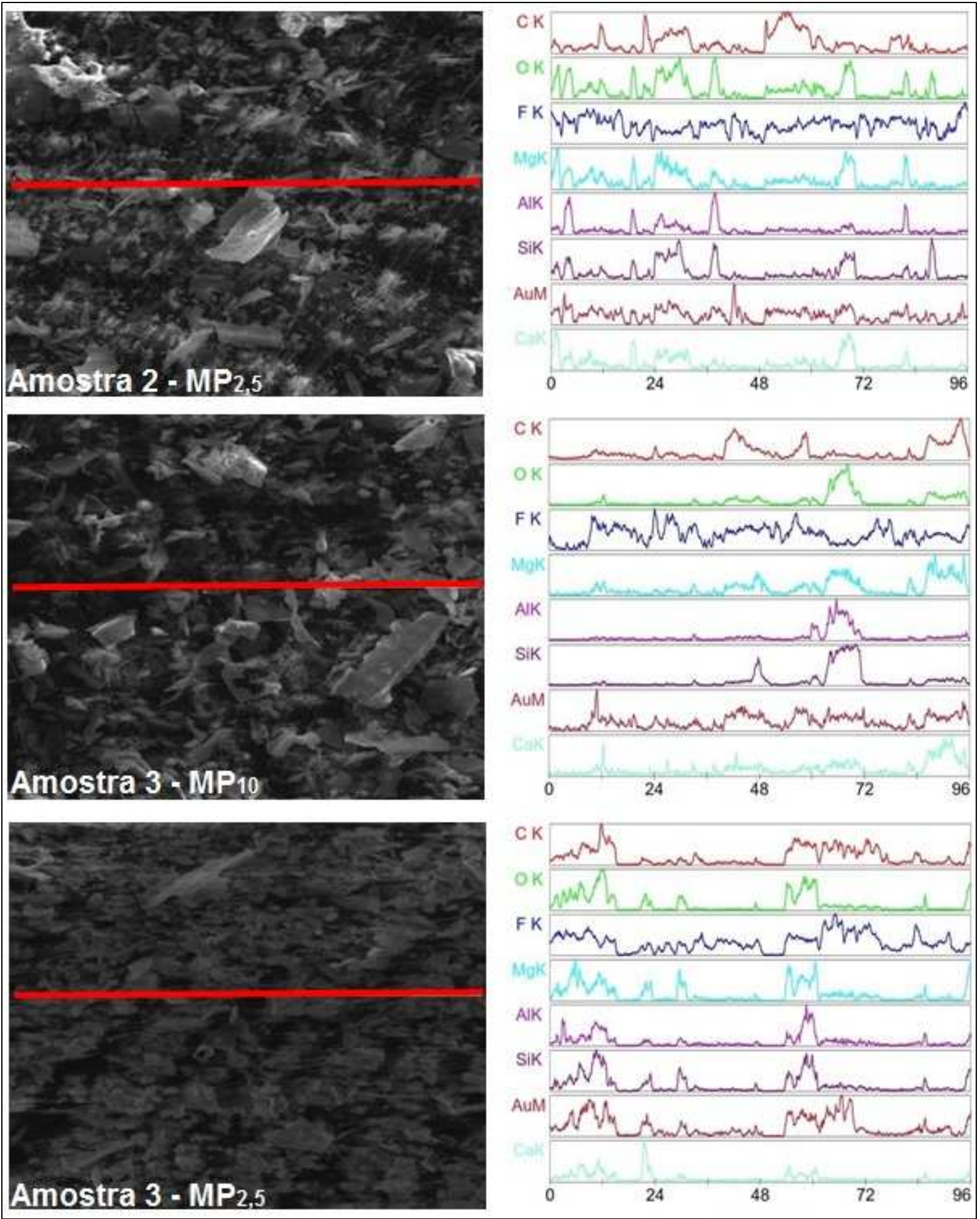

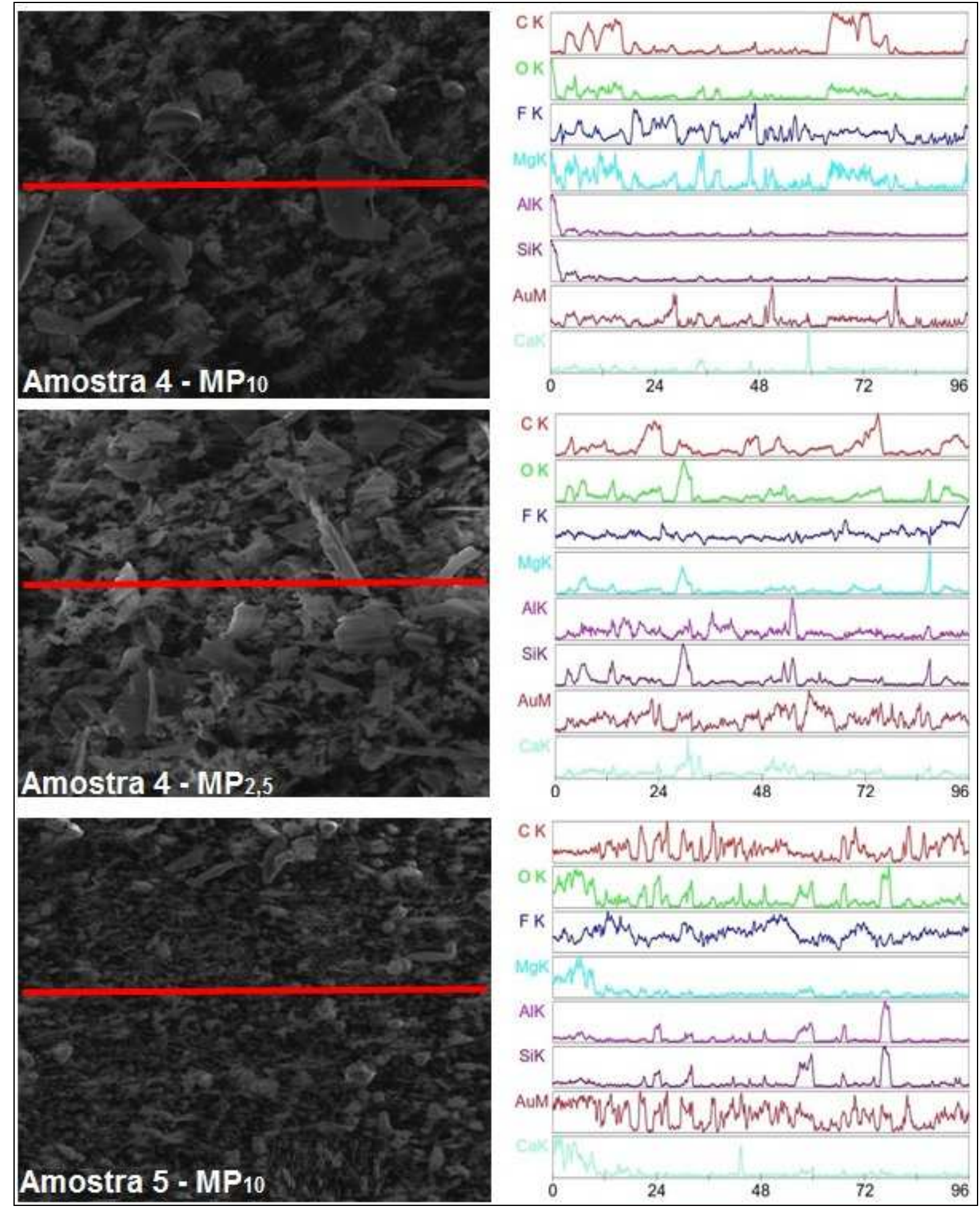


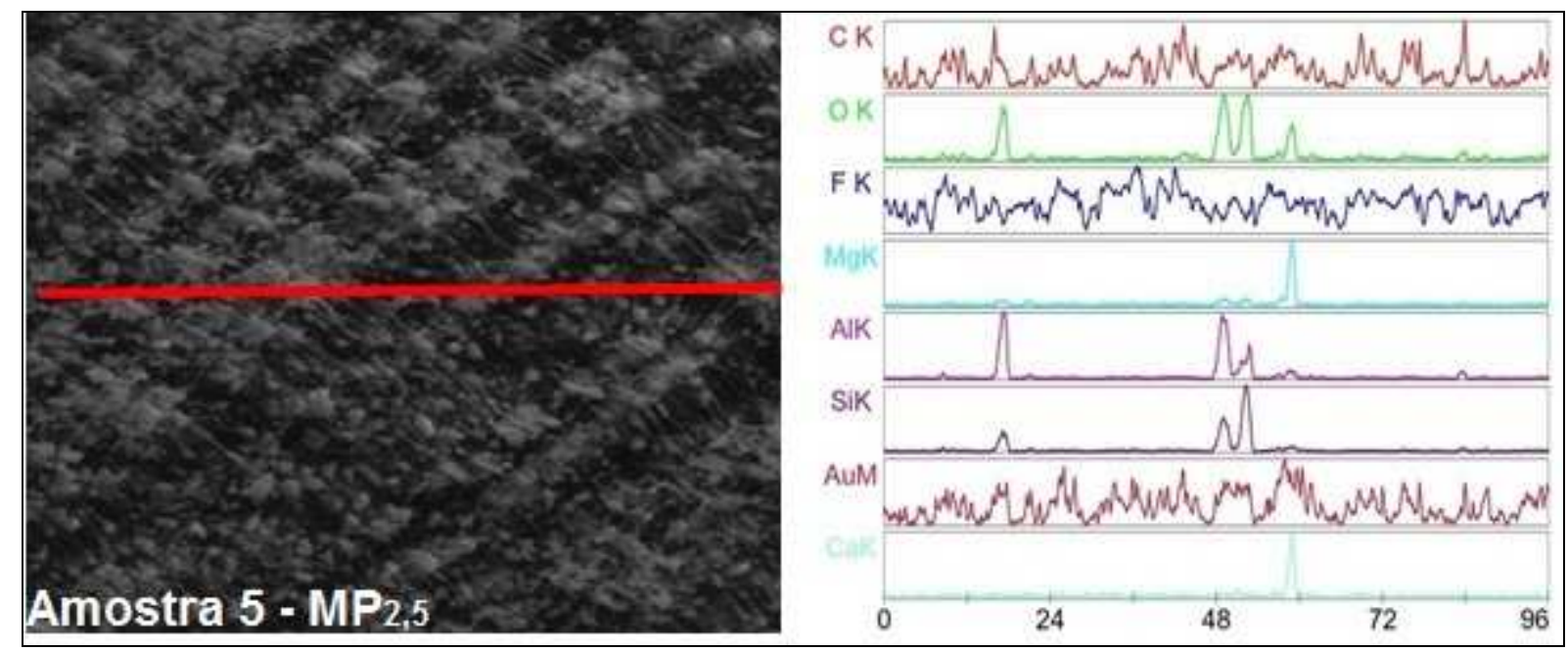

FIGURA 8 (a)- (j) - Análise física e linha de composição dos elementos químicos Fonte: Arquivo pessoal.

Por intermédio da análise física, foi constatado que o particulado coletado apresenta geometrias irregulares, pontiagudas e esféricas, que representam a vasta diversidade de elementos aos quais os usuários do laboratório são expostos diariamente. Com a composição química pontual, foi verificado os elementos Carborno (C), Oxigênio (O), Flúor (F), Magnésio (Mg), Alumínio (Al), Silício (Si), Ouro (Au) e Cálcio (Ca).

$\mathrm{O} \mathrm{C}, \mathrm{O}$ e $\mathrm{F}$ foram os elementos de maiores concentrações e não foram detectados na técnica de $\mathrm{FRX}$ por serem elementos com número atômico próximo a 11. O elemento Au é proveniente do recobrimento com ouro, utilizado para melhorar a obtenção de resultados. Já o Mg, Al, Si e Ca apresentaram baixas concentrações quando comparados com os demais.

Resultados semelhantes podem ser verificados também nos trabalhos de Comin (2012), Melo Júnior (2007) e Pozza (2005).

\section{Temperatura e Umidade relativa}

Os valores de temperatura e umidade foram monitorados interna e externamente, registrando-se os valores ao início e ao término de cada amostragem.

A Tabela 4 dispõe as médias aritméticas dos valores amostrados dentro e fora do laboratório, bem como a divisão entre os valores internos e externos de temperatura e umidade relativa (índice I/E).

Pode-se constatar que todos os índices foram muito próximos de 1, sugerindo que os dois ambientes apresentaram temperatura e umidade relativa parecidas.

TABELA 4 - Médias de temperatura e umidade relativa e índice I/E

\begin{tabular}{ccccccc}
\hline Dia & \multicolumn{3}{c}{ Temperatura ( $\left.^{\circ} \mathbf{C}\right)$} & \multicolumn{3}{c}{ Umidade relativa (\%) } \\
& Externa & Interna & Índice I/E & Externa & Interna & Indice I/E \\
\hline 1 & 16,6 & 18,5 & 1,11 & 74,8 & 74,6 & 0,99 \\
2 & 20,8 & 20,9 & 1,00 & 55,5 & 55,0 & 1,00 \\
3 & 23,6 & 23,2 & 0,98 & 47,7 & 49,0 & 1,02 \\
4 & 25,6 & 24,0 & 0,94 & 45,4 & 50,0 & 1,10 \\
5 & 24,9 & 23,6 & 0,95 & 45,2 & 45,7 & 1,01 \\
\hline
\end{tabular}

Fonte: Elaborado pelas autoras. 
Para facilitar a compreensão dos dados expostos na Tabela 4, as Figura 9 e 10 evidenciam a temperatura externa e interna e a umidade relativa externa e interna, respectivamente.

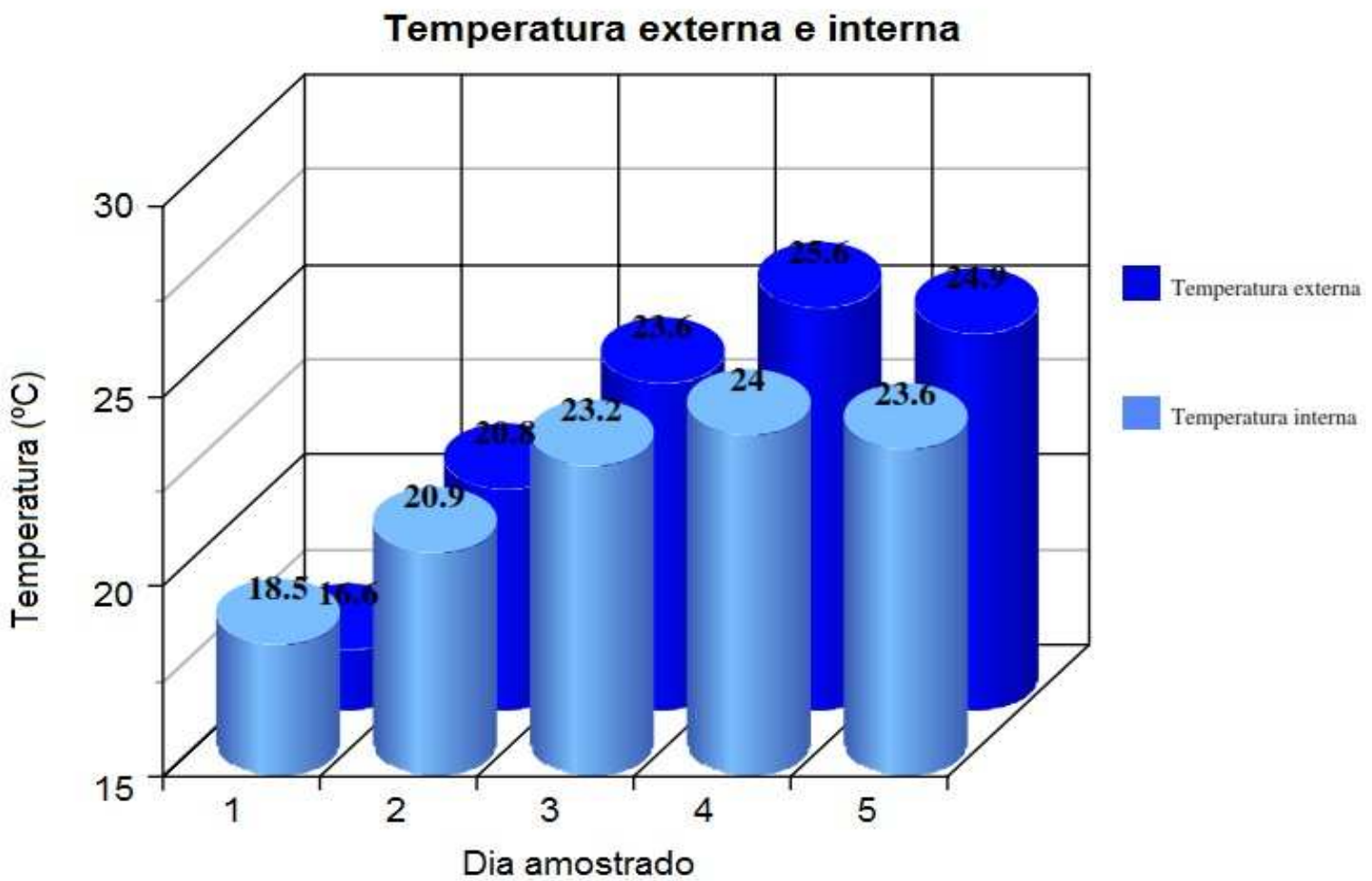

FIGURA 9 - Gráfico com as temperaturas monitoradas Fonte: Elaborado pelas autoras.

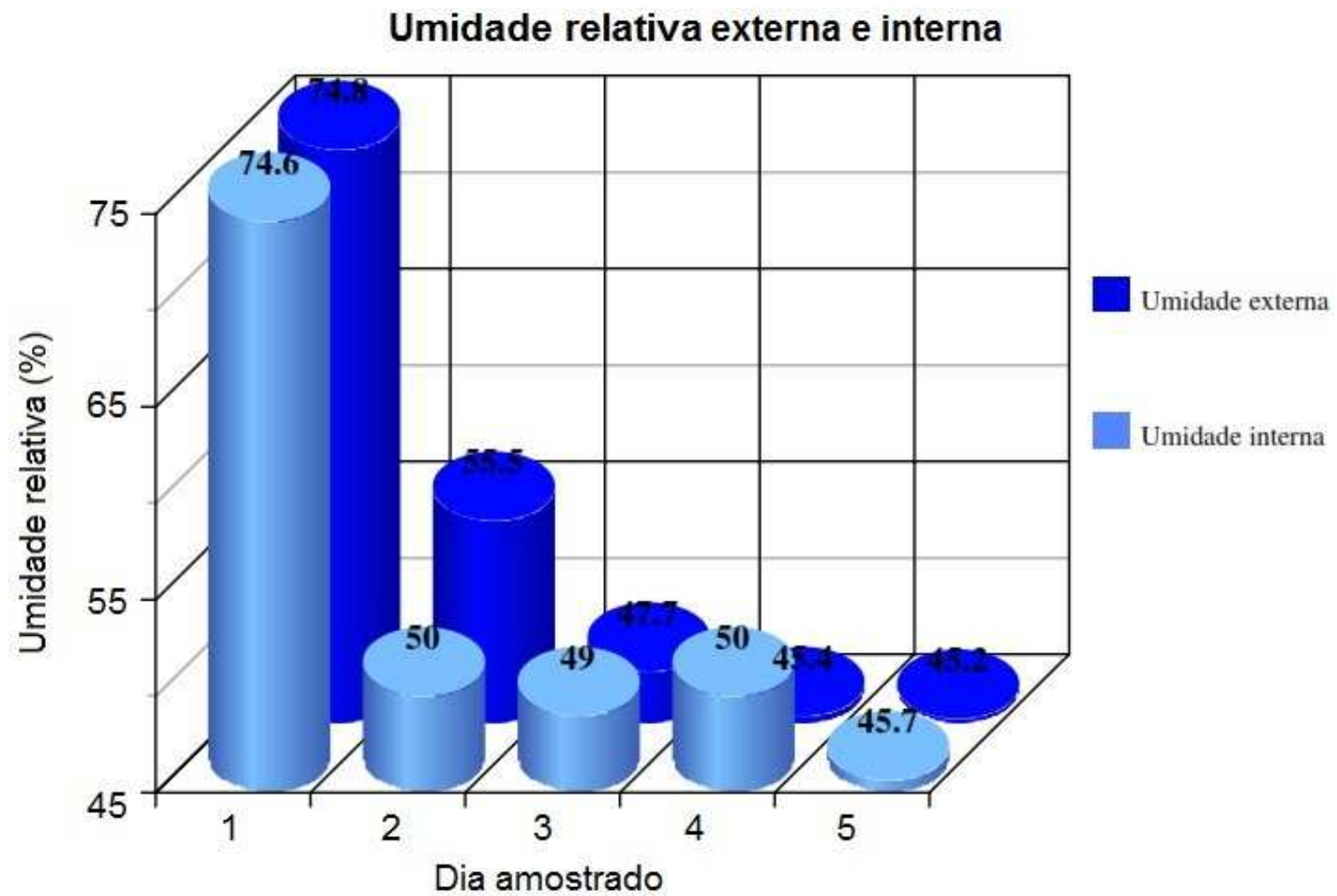

FIGURA 10 - Gráfico com as umidades relativas monitoradas Fonte: Elaborado pelas autoras. 
A média das temperaturas internas monitoradas foi de $22,0^{\circ} \mathrm{C}$, e conforme 0 Instituto Nacional de Pesquisas Espaciais (INPE), o inverno iniciou-se às $13 \mathrm{~h} 38$ do dia 21 de junho de 2015 e perdurou durante os meses de junho, julho e agosto. Portanto, como o monitoramento ocorreu nos dias de agosto, essa é a estação do ano que representa o estudo.

A Resolução - RE ํㅜ 9, de 16 de janeiro de 2003 da AGÊNCIA NACIONAL DE VIGILÂNCIA SANITÁRIA (ANVISA), recomenda que a temperatura do interior de um ambiente no verão, esteja na faixa média entre $23^{\circ}$ a $26^{\circ} \mathrm{C}$ e, no inverno, entre $20^{\circ}$ a $22^{\circ} \mathrm{C}$. Logo, a média obtida para as temperaturas internas está dentro do proposto pela legislação vigente.

Já para a umidade relativa, a Resolução - RE no 9, de 16 de janeiro de 2003 da AGÊNCIA NACIONAL DE VIGILÂNCIA SANITÁRIA (ANVISA), recomenda que os níveis estejam compreendidos na faixa média entre 40 a $65 \%$ no verão e 35 a $65 \%$ no inverno. A média das umidades relativas internas monitoradas foi de $54,9 \%$, estando também adequada conforme os padrões estabelecidos.

\section{CONCLUSÕES}

Mesmo que o presente estudo não se ajuste às condições estabelecidas nas legislações vigentes, foi observado que todas as amostras de $M_{10}$ e $M_{2,5}$ apresentaram altas concentrações, extrapolando os valores recomendados.

Esse fato interfere de modo significativo nas questões de saúde pública, uma vez que a exposição a partículas inferiores a 2,5 $\mu \mathrm{m}$ comprometem o sistema respiratório dos humanos. Além disso, outras enfermidades podem estar associadas com a via de exposição direta a esses particulados, como por exemplo, as alergias, as irritações das mucosas nasais, as doenças de pele, olhos e ouvidos.

As análises químicas do MP coletado identificaram os elementos: $\mathrm{Ca}, \mathrm{Cu}, \mathrm{Fe}$, $\mathrm{K}, \mathrm{S}, \mathrm{Si}, \mathrm{Ti}$, além de $\mathrm{C}, \mathrm{O}, \mathrm{F}$ e Mg, que possivelmente são provenientes de emissão veicular, queima de vegetação rasteira e biomassas, ressuspensão de solo, combustão industrial e utilização de giz nas salas de aulas próximas ao local amostrado.

A análise física permitiu o conhecimento da variada gama de geometrias dos particulados coletados, o que nos permite inferir que há uma infinidade de partículas presentes no ar aos quais os seres vivos estão expostos.

Os valores das médias de temperatura e umidade relativa monitoradas ficaram dentro do que é recomendado pelas normas disponíveis. Dessa forma, o ambiente interno pode ser considerado como um ambiente confortável e com probabilidade baixa de proliferação de microrganismos.

Diante do que foi exposto, embora o estudo em questão tenha permitido a abordagem sobre a poluição atmosférica com ênfase na qualidade do ar interior, outros se fazem necessários, para possibilitar a melhor compreensão da área e favorecer a criação de normas específicas.

Faz-se necessário também a realização de monitoramentos contínuos neste tipo de ambiente interno, visto que é um local de múltiplos acessos, e as condições do local são alteradas a todo instante, podendo interferir nas concentrações tanto de $\mathrm{MP}_{10}$ quanto de $\mathrm{MP}_{2,5}$.

\section{REFERÊNCIAS}

AGÊNCIA NACIONAL DE VIGILÂNCIA SANITÁRIA (ANVISA). PORTARIA no 3523. Brasília, 1998. 11 p. 
RE 09: qualidade do ar ambiental interior. Brasília, 2003. 10 p.

ANDREOLI, Cleverson Vitorino. Principais Resultados da Política Ambiental Brasileira - O Setor Público. Subsídio para o Relatório do Brasil para a CNUMAD. (mimeo). Curitiba, abril/1991.

ASSOCIAÇÃO BRASILEIRA DE REFRIGERAÇÃO, AR CONDICIONADO, VENTILAÇÃO E AQUECIMENTO (ABRAVA). RN 02: sistemas de condicionamento de ar e ventilação para conforto, qualidade do ar interior. São Paulo, 2003. 18 p.

COMIN, T. T. Monitoramento ambiental em uma escola da cidade de São Carlos - SP. 2012166 f. Dissertação (Mestrado em Engenharia Química) - Departamento de Engenharia Química (DEQ), Universidade Federal de São Carlos, São Carlos 2012.

EMPRESA BRASILEIRA DE PESQUISA AGROPECUÁRIA (EMBRAPA). Dados meteorológicos.

Disponível em: <http://www.cppse.embrapa.br/dados-meteorologicos>. Acesso em: 01 ago. 2015.

GONÇALVES JUNIOR, S. J. Avaliação da participação de material particulado e seus impactos à saúde humana em escolas próximas a vias de tráfego veicular e refinaria de petróleo. 201495 f. Dissertação (Mestrado em Engenharia e Ciência dos Materiais) - Setor de Tecnologia, Universidade Federal do Paraná, Curitiba 2014.

INSTITUTO BRASILEIRO DE GEOGRAFIA E ESTATÍSTICA (IBGE). Censo 2014. Disponível em:

<http://www.ibge.gov.br/home/estatistica/populacao/censo2014/default.shtm>. Acesso em 29 jul. 2015.

INSTITUTO NACIONAL DE PESQUISAS ESPACIAIS (INPE). Centro de Previsão de tempo e estudos climáticos. Disponível em:

<clima1.cptec.inpe.br/estacoes>. Acesso em 30 de ago. 2015.

MAIOLI, B. G. Quantificação e caracterização do material particulado fino $(2,5)$ na região metropolitana da grande Vitória - ES. 118 f. Dissertação (Mestrado em Engenharia Ambiental) - Centro Tecnológico, Universidade Federal do Espírito Santo. Vitória, 2011.

MANNHEIMER, W. Microscopia dos Materiais - Uma Introdução. E-papers, edição: Sociedade Brasileira de Microscopia e Microanálise, 2002.

MATSUMOTO, E. Estudo da contaminação ambiental atmosférica e de águas superficiais, empregando a fluorescência de raios $X$ dispersiva em energia (EDXRF) e reflexão total. 2001. 150 f. Tese (Doutorado em Engenharia Civil) Faculdade de Engenharia Civil, Universidade de Campinas, Campinas 2001.

MELO JÚNIOR, A. S. Análise quantitativa do material particulado na região de campinas através das técnicas de microfluorescência de raios-X e reflexão ENCICLOPÉDIA BIOSFERA, Centro Científico Conhecer - Goiânia, v.11 n.22; p. 3365 
total usando radiação síncrotron. Tese (Doutorado em Química) - Unicamp, Campinas, São Paulo, 2007.

NASCIMENTO FILHO, V. F. Técnicas analíticas nucleares de fluorescência de raios $X$ por dispersão de energia (EDXRF) e por reflexão total (TXRF), Piracicaba: Departamento de Ciências Exatas - ESALQ/USP; Laboratório de Instrumentação Nuclear - CENA/USP, 1999. 33 p.

POZZA, S. A. Identificação das fontes de poluição atmosférica na cidade de São Carlos - SP. 2005. 119 f. Dissertação (Mestrado em Engenharia Química) Centro de Ciências Exatas e de Tecnologia, Universidade Federal de São Carlos, 2005.

ROSA, P. F. Avaliação dos efeitos de suspensões de nanopartículas de prata (AgNP) na erradicação de bactérias e fungos encontrados em material particulado. 2014103 f. Dissertação (Mestrado em Engenharia Química) Departamento de Engenharia Química (DEQ), Universidade Federal de São Carlos, São Carlos 2014.

SKC. Personal Environmental Monitor for measurement of $\mathbf{P M}_{10}$ and $\mathbf{P M}_{2,5}$ indoor air. Disponível em: <http://www.skcinc.com/instructions/1367.pdf>. Acesso em 5 ago. 2015.

UNIVERSIDADE FEDERAL DE SÃO CARLOS (UFSCar). A universidade. Disponível em:

< http://www2.ufscar.br/aufscar/auniversidade.php>. Acesso em 24 set. 2015. 